\title{
Updated and outdated reservations about research into stratospheric aerosol injection
}

\author{
Wake Smith ${ }^{1,2}$ (D) Claire Henly $^{3}$
}

Received: 30 July 2020 / Accepted: 2 February 2021/Published online: 11February 2021

(C) The Author(s) 2021

\begin{abstract}
In this paper, we seek to ground discussions of the governance of stratospheric aerosol injection research in recent literature about the field including an updated understanding of the technology's deployment logistics and scale, pattern of effects, and research pathways. Relying upon this literature, we evaluate several common reservations regarding the governance of pre-deployment research and testing including covert deployment, technological lock-in, weaponization, slippery slope, and the blurry line between research and deployment. We conclude that these reservations are no longer supported by literature. However, we do not argue that there is no reason for concern. Instead, we enumerate alternative bases for caution about research into stratospheric aerosol injection which are supported by an up-to-date understanding of the literature. We conclude that in order to establish the correct degree and type of governance for stratospheric aerosol injection research, the research community must focus its attention on these wellgrounded reservations. However, while these reservations are supported and warrant further attention, we conclude that none currently justifies restrictive governance of early-stage stratospheric aerosol injection research.
\end{abstract}

Keywords Governance - Slippery slope $\cdot$ Moral hazard - Stratospheric aerosol injection · Greenfinger $\cdot$ Covert deployment $\cdot$ Geoengineering

Key points 1 . Recent literature on deployment logistics and scale, pattern of effects, and research pathways undermines several common reservations about early-stage stratospheric aerosol injection research.

Wake Smith

wake.smith@yale.edu

1 Yale College, New Haven, CT, USA

2 Mossavar-Rahmani Center for Business and Government, Harvard Kennedy School, Cambridge, MA, USA

3 Harvard Kennedy School, Cambridge, MA, USA 
2. There are, nonetheless, many reservations about stratospheric aerosol injection research which are well supported by the literature and merit greater attention.

3. No well-supported reservations about stratospheric aerosol injection justify restrictive governance of the technology's early-stage research.

\section{Introduction}

Though the study of stratospheric aerosol injection (SAI) has evolved from its status as a "former pariah" (Kintisch, 2010) to the periphery of scholarly respectability, views on the proper governance of SAI research remain tainted by early misunderstandings of this prospective climate intervention. Prior to Crutzen's 2006 clarion call (Crutzen, 2006), the geoengineering field was generally considered taboo due to concerns that pursuing it would hamper emissions reductions efforts. While the annual output of scholarly papers has since multiplied from a trickle to a steady stream, views on SAI research governance have often run ahead of a detailed understanding of the technology and have failed to incorporate new research in the field. As a result, restrictive SAI research governance regimes are out-of-date, limiting funding for the field in general and diverting attention away from research into reservations which are well supported. In this paper, we establish an updated vision of the supported and unsupported reservations about research into SAI.

SAI is emerging as a potential option to limit the effects of climate change. In fact, in the 2018 Intergovernmental Panel on Climate Change (IPCC) Special Report on Global Warming, all of the $1.5{ }^{\circ} \mathrm{C}$ scenarios (and most of the in the $2{ }^{\circ} \mathrm{C}$ scenarios) required additional climate interventions, beyond emissions reductions, to remain within their limits (IPCC 2018). While carbon removal in the form of afforestation, reforestation, and bio energy with carbon capture and storage were cited in the report (IPCC 2018), other climate interventions are also being considered with increasing urgency (Pierce, 2019). Among those is SAI, whereby a thin layer of aerosol particles would be deployed over the earth to deflect a small fraction of incoming sunlight and slightly cool the planet in roughly the same way that large volcanic eruptions occasionally do (Rasch et al., 2008a).

According to its detractors, SAI is an arrogant technofix (Jamieson, 1996; Scott 2012; Preston 2013) that belongs to a category of emergent technologies so dangerous that their exploration (let alone deployment) must be subjected to restrictive governance (Hamilton, 2013a; Bodle et al., 2014; Hubert 2017). For example, Bodle et al. (2014) recommend a prohibition on field tests (allowing the possibility for exceptions), while Hamilton (2013a) suggests that research should be put on pause until there are means to control deployment. In this paper, we conclude that several of the most common reservations about the exploration of SAI tend to be based on out-of-date understandings of the technology's deployment logistics and scale, pattern of effects, and research pathways, and do not justify restrictive governance of early-stage research.

Nevertheless, we do not conclude that there is nothing to fear in SAI research. However, where we do find reasons for caution in this early stage, we do not conclude that the appropriate response is to restrict SAI research. Instead, we recommend that the SAI research community prioritizes addressing supported reservations with research and governance.

A few disclaimers before we begin. First, while we have endeavored to present global perspectives in this paper, as researchers from the USA, we are predisposed to view this issue from the vantage point of a well-endowed super power and the reader should be aware of this potential bias. Second, our paper pertains only to the research of SAI and, quite specifically, 
not to its deployment, and that we limit our purview only to SAI and not solar radiation management or geoengineering more broadly. Finally, by early-stage research, we mean all research (including field research) up to the stage of pre-deployment climate response tests.

\section{Unsupported governance reservations}

Several major reservations about stratospheric aerosol injection are used to justify recommending restrictions on its research (Jamieson, 1996; Victor, 2008; Preston et al. 2012; Gardiner, 2009; Fleming 2010; Hulme, 2014; Cairns, 2014). Next, we discuss those reservations which are undermined by recent literature on SAI.

\subsection{Covert deployment}

One reservation that motivates a subset of those who seek to limit SAI research is the prospect of covert deployment, wherein a rogue actor attempts to geoengineer the world without international knowledge or consent (Victor, 2008). The rogue actor could be a climatedamaged country or a large corporation, but is more colorfully envisioned as "Greenfinger" (Victor, 2008), "a self-appointed protector of the planet."

Recent research into SAI has begun to illuminate what deployment in the next few decades would require aeronautically, operationally, and financially. Irrespective of which aerosols are lofted in an SAI program, for them to endure in the atmosphere for 12 to 18 months rather than a few days, they must be dispersed at an altitude of roughly $20 \mathrm{~km}$ (Rasch et al., 2008a; Rasch et al. 2008b; Pierce et al. 2010) — nearly double the normal airliner cruising altitude. To cool the earth by a substantial amount-say $1{ }^{\circ} \mathrm{C}$ - one would have to loft roughly five million metric tons of aerosols annually to this high perch (Smith, 2020). Once started, the deployment would need to be continuous or the cooling effect would cease (Pierce et al. 2010). By far, the cheapest way to haul this enormous mass of material to the lower stratosphere year-round, for decades, would be via a fleet of newly designed, airliner-sized, high-altitude tankers (McClellan et al., 2012; Smith \& Wagner, 2018). A fleet large enough to loft five million tons of aerosols annually to the stratosphere would be on the order of 150 aircraft and require an annual budget on the order of \$18 billion in 2020 USD (Bingaman et al., 2020; Smith, 2020). While the fleet and deployed mass requirements noted here assume a thoughtful injection program intended to be global in impact and hemispherically balanced, even a program intended to cool just one region would require a quarter to half the activity required for a global program, rendering it still a massive endeavor.

Given these deployment observations, it is highly unlikely that an SAI program could be carried out covertly at a scale large enough to substantially alter the climate. While SAI would be dramatically cheaper than other climate interventions (Ackerman \& Stanton, 2007; Wagner \& Weitzman, 2015), a globally substantial intervention would still be a massive industrial undertaking, involving hundreds of planes, thousands of employees, an extensive supply chain, and enormous financial resources (McClellan et al., 2012; Smith, 2020). The activity required not only to fly these aircraft but to purchase, maintain, and base them would be readily detectable not only by multiple intelligence services but by civilian satellites selling observational data to the general public (Philippe 2019; Foust, 2019). Any climate-altering SAI program would involve far too much industrial activity to hide and, as a result, we conclude that covert deployment is no longer a valid reservation about SAI. 


\subsection{Non-state deployment}

A second reservation wrapped up in the Greenfinger scenario (Victor, 2008) is non-state deployment. However, given we now conclude that a reservation around covert deployment is unsupported, the non-state reservation quickly fails to stand up to reason. Recent literature finds that a climate-altering SAI program would exceed the financial grasp of individuals, terrorist groups, NGOs, and small states (Reynolds, 2018; Smith, 2020). Pre-start capital costs would require several billion USD (Smith \& Wagner, 2018), and the ongoing, annual cost to change global climate by $1{ }^{\circ} \mathrm{C}$ is roughly US $\$ 18$ billion (Smith, 2020). These costs would quickly drain the fortunes of even the world's wealthiest individuals and surpass the annual military budget of all but perhaps a dozen countries.

Even if a non-state actor could amass the fortune required to fund a climate-altering SAI operation, they would require territorial sovereignty to carry it out (Horton 2019) and the military wherewithal to defend the program from a likely hostile uninvolved world (Parson, 2014). We therefore conclude that deployment by non-state actors is no longer a supported reservation about SAI. SAI can only be undertaken by a major state (or a coalition including such a state), in full view of the world, with both the will and the might to defend such a program (Parson, 2014).

\subsection{Weaponization and threat multiplier}

Another oft-cited reservation about SAI research is that the end product might be weaponized (Fleming 2010). However, recent research calls into question this claim. Dai et al. (2018) shows that SAI deployment would affect everyone from the injection latitude poleward (Dai et al., 2018). Given this, it is hard to see how SAI could be "weaponized." In the most comprehensible weaponization paradigm, a country would geoengineer its poleward neighbor, but not itself. For instance, the USA could inject over Duluth, "geoengineering" Canada while largely sparing itself (but for Alaska). The problem for the USA is that the impact on Canada cannot be limited to Canada. Equally affected would be the UK, Northern Europe, and, most ominously, Russia (Dai et al., 2018), all of whom would join Canada in objecting (at least on procedural grounds). Moreover, the entire world would be affected by the increase in the equator-to-North Pole temperature gradient creating weather changes in the tropics. Cloud modifications, should they ever prove practicable, could be undertaken locally or regionally, but are outside the scope of this paper. SAI appears difficult to deploy regionally rendering it not "targetable" and an impractical weapon.

A related reservation about SAI is that it will exacerbate existing political, social, and other threats; i.e., it will be a threat multiplier. Climate change is often portrayed as a threat multiplier because its foreseeable impacts - such as increased water shortages, desertification, droughts, and extreme weather-could destabilize societies and inflame pre-existing political rifts (Holland \& Vagg, 2013). Briggs (2013) argues that SAI should also be considered a threat multiplier because, while it may create a net climate benefit, it may change environmental systems in a way that still disrupt underlying social, political, and economic structures.

Recent research by Irvine et al. (2019) calls into question this conclusion. While much research remains to be completed, at this early juncture, the best available study indicates that if the world is subdivided into the 26 regions used by the IPCC for impact analysis and examined in respect of the climate outcomes that matter most to local human populations, moderate SAI would make all regions better off on some or all of the outcome variables and 
worse off on none (Irvine et al., 2019). Therefore, moderate SAI appears to be a benefit rather than a threat. We do recognize that the coarse scale of current analytical tools may mask more unequal impacts at a finer scale, but Irvine et al. (2019) still call into question the assumption that regions will "lose" from deployment. If SAI proves to be an intervention that returns regional conditions closer to their status quos, it will reduce the threat multiplication effects of climate change and be restorative rather than disruptive.

\subsection{Blurry line}

Another common critique is that the line between SAI experimentation and full-scale deployment is so blurry it is meaningless. Critics have asserted that little useful knowledge about the impacts of SAI can be gained before full-scale deployment and that deployment may be undertaken under the guise of research (Robock et al., 2010; Hulme, 2014). Robock et al. (2010) have argued that testing SAI would be impossible without its full-scale deployment. In the same vein, Hulme (2014) claims that the only experimental method for adequately testing system-wide response to SAI is to subject the planet itself to the full treatment. However, once one understands the small scale of near-term SAI research efforts and the huge scale of deployment, it becomes clear that what is characterized as a blurry line is in fact a vast gulf.

As of this writing, SAI research has yet to significantly migrate out of the laboratory and into the field. A 2009 experiment, led by Russian researcher Yu Izrael, which tested how solar radiation passes through aerosol layers (Izrael et al., 2009), is the only SAI field test to date. The SPICE project - a 2015 field test in the UK - never got off the ground (Stilgoe 2015). Harvard's Solar Geoengineering Research Group hopes to launch Stratospheric Controlled Perturbation Experiment (SCoPEx) in the coming year, but the governance panel appointed to pass judgment on the project has yet to issue a green light. SCoPEx would deploy a 2-kg payload per flight for the purpose of exploring the microphysics and atmospheric chemistry of aerosol particles in the stratosphere (Keutsch Research Group 2020).

A recent paper by MacMartin and Kravitz (2019) concludes that the next questions in SAI research will likely be answered primarily via computer models, with small-scale field experiments, such as SCoPEx, required to constrain the model parameterizations. Lenferna et al. (2017), building upon an earlier ascending taxonomy of field research proposed by Keith et al. (2014), also find that the next stages of SAI research do not require large-scale testing. The first small-scale, localized process experiments, like SCoPEx, would later proceed to scaling tests, larger in scope but still dispersing less material than is incidentally spewed by long-haul a commercial airline flight, and over a much smaller geographical region (Keith et al., 2014). Lenferna et al. (2017) next propose a phase of albedo response tests seeking to measure changes in the earth's reflectivity. These would, for the first time, be global in geographic scope, but still modest in radiative forcing, duration, and climate impact (Lenferna et al., 2017). Only the subsequent climate response tests (CRTs) would begin to approach deployment in terms of scale (Lenferna et al., 2017). We are likely decades from being sufficiently confident in the promise of SAI (and frightened by further unabated climate change) to wish to undertake CRTs (Floerchinger et al. 2020).

Compared to the modest experimental payloads necessary for testing in the coming years, and even decades (Lenferna et al., 2017; MacMartin and Kravitz 2019), a year-one full-scale deployment program might entail 6500 flights to deploy 200,000 tons of aerosols (Smith \& Wagner, 2018). This massive initial deployment would have an impact of just two one hundredths of a degree Celsius of cooling (Smith \& Wagner, 2018). The year-five deployment 
of a million tons would still only change temperatures by just one-tenth of a degree (Smith \& Wagner, 2018). The leap from experimental masses to implementation would entail scaling up the program by at least two, and likely three, orders of magnitude (Smith \& Wagner, 2018).

Therefore, a much fairer characterization is that the last stage of pre-deployment testing would indeed begin the approach the scale of deployment, but that the many steps required between here and there would look nothing like deployment and would reveal a great deal. Seeking to ban process experiments in the field intended to clarify questions such as microphysical evolution of aerosols in the stratosphere and which will have no impact on the earth's climate is rash and unwarranted.

\subsection{Slippery slope and technological lock-in}

Finally, it is commonly proclaimed that any serious consideration of SAI creates the risk of an inexorable descent down a slippery slope to deployment (Jamieson, 1996; Hulme, 2014; Stilgoe 2015). Several authors have endeavored to connect SAI momentum to an inescapable causal chain. Hamilton (2013b) claims that "On the slippery slope, technologies gather added political momentum because we live in societies predisposed to seek technological answers to social problems." Hulme (2014) adds that "Once SAI technology has reached a certain scale of development, the next stage of development is easily justified... momentum grows until fullscale deployment eventually becomes unstoppable." Jamieson (1996) suggests that institutional momentum among researchers will propel the technology to deployment.

Two recent studies undermine the slippery slope argument. First, Callies (2019) finds that no literature has proven that the slippery slope effect is more true for geoengineering than other technologies. Jamieson (1996) makes the most valiant attempt to identify a causal chain specific to climate engineering, but can assert only that the technology will experience similar institutional momentum to other research efforts. This argument is insufficient to prove why climate engineering should be more subject to slippery slope than any other research-based technological effort. Second, Bellamy and Healey (2018) find that momentum (both research and commercial) for climate engineering deployment broadly is lacking. Using a survey-based method, the researchers identified so many obstacles to climate engineering, they concluded that the "challenges for climate engineering should... be thought of as less of a slippery slope than an "uphill struggle" (Bellamy \& Healey, 2018).

Rather than institutional momentum, we believe the most compelling, hypothesized causal chain for SAI is that fossil fuel or commercial interests may drive it forward. We find these reservations are supported both in the case of fossil fuel interests and in the case of SAI at later stages of deployment (see below). However, in the research phase, commercial profit interests have proven insufficient to attract investors big or small.

A related argument pertains to technological lock-in, in which market failures enable a weaker solution to prevail over stronger ones (Arthur, 1989; Liebowitz \& Margolis, 1995; Stilgoe 2015). Stilgoe (2015) asserts: "The history of technology tells us that innovation is 'path dependent' and prone to 'lock in', which can result in the triumph of bad technologies... Geoengineering is already being scientized, creating lock-in and path dependency that may prove irreversible."

As with slippery slope, the operative question related to technological lock-in should be whether SAI is subject to path dependency either to an unusually high degree or in an unusually harmful manner. To answer this question, it is helpful to clarify what other, better technologies SAI is at risk of crowding out. It is possible that SAI could crowd out other 
geoengineering solutions, such that once the SAI aircraft fleet was on the flight line, the world might be less inclined to invest in marine cloud brightening or direct air capture and carbon sequestration (DACCS). That is possible, but unlikely. The commercial potential of DACCS is roughly three orders of magnitude larger than that of SAI (Harding and Moreno-Cruz 2019; Roberts, 2019; Smith, 2020), so if commercial interests begin pushing for a governmental geoengineering response, the dollars will back DACCS rather than SAI. For the same reason, if the business case solidified for DACCS even after an SAI deployment commenced, the "sunk cost" associated with the SAI infrastructure would be (given its relative low costs) an immaterial barrier to the evolution of a far larger DACCS program. The carbon capture industry is nascent but alive (Elliott, 2020), whereas we count the number of companies in SAI as exactly zero.

Perhaps the best argument against slippery slope or technological lock-in reservations about SAI research is current evidence. Fifteen years have passed since Crutzen's 2006 geoengineering clarion call, and the "slope" confronting SAI remains decidedly an incline rather than a decline (Bellamy \& Healey, 2018) with only one field test in the planning phase (Keutsch Research Group 2020). Given the above literature and the slow progress of research, we conclude that SAI is no more prone to slippery slope or technological lock-in than other technology in the research phase.

\section{Supported research governance reservations}

Even though we conclude above that several common reservations about research into SAI are no longer supported, we do not suggest that we should plunge forward in SAI research without forethought or prudence. Research into any novel climate intervention with substantial transboundary effects and potentially unforeseen consequences warrants caution, and there are many well-supported governance reservations that SAI researchers should consider. The harms that may result from these supported reservations are of two sorts. The first threatens damage to efforts to reduce emissions. The remainder threaten to damage a thoughtful and effective SAI program itself by rendering it suboptimal or impracticable.

While the reservations about potential harms are well supported, we argue, in all cases, that they would not be ameliorated by a ban on research. Instead, most reservations would be best addressed by being the focus of research. As a result, we argue that none of the well-supported reservations justifies restrictive research governance such as a ban on field tests.

\subsection{Moral hazard}

For those who believe that SAI research should be discouraged, the argument generally cited first and foremost is often referred to as "moral hazard" (Preston et al. 2012; The Royal Society and Shepherd 2009; Lin, 2013). SAI critics assert that knowledge of alternative or supplemental methods to address climate change and its impacts may reduce the motivation of current and future generations to undertake the urgent and arduous task of emissions reduction (Preston et al. 2012; Lin, 2013).

We do not suggest that the moral hazard risk is insubstantial. However, we (along with many others in the field) do not determine that the right response is to limit SAI research in a bid to shroud the future in ignorance and foreclose to it certain options (Wagner and Merk 2019). 
Seeking to hide knowledge from the future is the wrong response for several reasons. First, it is indefensible from the standpoint of intergenerational justice. Our generation (with generous contributions from immediately preceding generations) will likely bequeath to our descendants a substantially degraded environment and a breathtaking carbon "debt" which they will struggle mightily to repay (Asayama \& Hulme, 2019). In such a context, is it justified for us to deprive future generations of tools that may lessen the pain we have inflicted? They may or may not use these tools, but surely those decisions are theirs to make.

Second, it is inconsistent. If the moral hazard argument is to be taken seriously, it must be applied not only to SAI but also to the other categories of non-mitigation climate defenses that the world is rapidly exploring, including adaptation and greenhouse gas removal technologies. These approaches would seek to decouple greenhouse gas concentrations from future climate damages and would thereby risk diminishing the incentive to reduce emissions. Should we therefore seek to strangle them in the crib for fear of the moral hazard they could engender as they mature?

Finally, it is futile to believe that research into SAI could remain a "secret." In a quick online search, we now find more than 1500 academic articles with "geoengineering" in the title, nearly all written since the turn of the century. Scholarly attention is rapidly accelerating and it is difficult to imagine any action that could stop the spread of existing research or curb future work.

Still, the moral hazard risk associated with SAI is real. It is easy to mistake SAI as a cheap and easy "solution to climate change" (Rotman 2013). It is not. Educating the world about not only the promise but also the potential perils and shortcomings of SAI is a burden which this field must accept.

\subsection{Fossil fuel infiltration}

One of the most material and timely apprehensions about SAI research is the prospect of the field being infiltrated by the fossil fuel industry in order to cultivate complacency about climate change and/or justify continued high fossil fuel use (Stanczyk 2019). Infiltration typically comes by way of corporate funding, an approach that was pioneered by tobacco industry when they funded medical experts to dispel fears about smoking (McKee, 2017). Research into the fossil fuel industry's approach to climate change denial shows similar tactics (Frumhoff \& Oreskes, 2015; Farrell et al., 2019).

One could imagine that the think tanks and policy advocates who currently seek to sow doubt about the existence, causes, and potential dangers of climate change might pivot to fullthroated advocacy for SAI and other forms of geoengineering as a way to justify continued fossil fuel emissions (Stanczyk 2019). Such false flag advocacy would abet rather than inhibit the sort of unwise substitutions noted in the discussion of moral hazard above by perhaps suggesting that all previous reasons to doubt the efficacy of SAI are resolved.

As a preemptive response, all efforts should be made to support research through government or other programs that do not rely on fossil fuel support and, as recommended by the Academic Working Group on Climate Engineering Governance, ensure that all research (including its funding sources) is made transparent and accountable (Chhetri et al. 2018; Jinnah 2019).

\subsection{Legitimacy deficit}

One major reservation about pursuing research into SAI is the challenge of how such a global climate intervention, affecting all humanity and living things, could ever achieve sufficient 
legitimacy. Beyond achieving a valid distribution of benefits and costs, such an undertaking would also need to be perceived as just in both participatory and procedural terms (Hourdequin, 2019) (i.e., more or less all of humanity was properly represented in a fair decision-making process). McLaren (2018) validates this fear by finding that current literature foreshadows procedural injustice by taking a purely utilitarian approach to outcomes.

A further governance reservation, especially from researchers outside of the USA, is that developed nations (or even a single superpower) will deploy geoengineering unilaterally without input from the rest of the world. In exploring this fear from an Indian perspective, Mathur and Roy (2019) note that "Above all, Indian policy makers are concerned about the prospect of unilateral action on geoengineering by developed nations." Given that the bulk of research on geoengineering to date has occurred within the boundaries of the world's most developed nations, this does appear to be a valid reservation. Even though the risk of unilateral deployment by small nation states is no longer supported, unilateral or mini-lateral deployment by a superpower remains so.

Such reservations may also intrude into the spiritual realm, with some questioning whether intentional interventions in the climate system are fundamentally permissible under any circumstances (Mathur and Roy 2019). All the more reason then why social scientists should be urgently called to begin to map a representative, legitimate consultation process.

While the world may find that it is impossible to establish true global legitimacy, we argue restricting SAI research is not the logical response to this fear. Instead, researchers should be aware of the risk and work to alleviate it by broadening SAI research and governance involvement through non-government organizations such as the Solar Radiation Management Governance Initiative, the aforementioned Academic Working Group on Climate Engineering Governance, and the Carnegie Climate Governance Initiative.

\subsection{Unilateral sub-scale deployment}

While unilateral deployment on a scale large enough to materially affect global climate would necessarily be a large-scale operation, SAI political provocations need not be. One can imagine that a sinking small island state or even a misguided "Greenfinger" (Victor, 2008) could fly an ineffective aircraft to an insufficient altitude and disperse an insignificant quantity of aerosol but announce "deployment" (Morton, 2015). Such a stunt would have negligible climate impact but might force SAI onto the global agenda more rapidly than is often assumed.

While extensive early research could perhaps facilitate rogue provocations, it would also better equip the world to accurately perceive sub-scale deployment as a political statement rather than a meaningful climate intervention.

\subsection{Multiple infrastructure development programs}

A significant risk is the prospect of multiple national or multilateral deployment programs. Implementing SAI in a manner that maximizes benefits and minimizes harms will be extremely challenging, in part because it may prove difficult to distinguish the SAI signal from the background climate change noise or from unrelated natural climate phenomena. Such attribution and programmatic tuning would be all the more difficult if there exist multiple, potentially uncoordinated, or even intentionally contradictory, simultaneous SAI programs, perhaps utilizing different aerosols and dispersal techniques in different locales. 
A key determinant of whether there is one or several such programs relates to the development of aeronautical infrastructure in the deployment and pre-deployment research stages. If the world develops separate national fleets of research and deployment aircraft, the likelihood is much greater that it will lead to separate deployment. If, instead, the world could converge on a single new research fleet, it would necessitate cooperative international institutions which could evolve into a single deployment governance program. It is therefore crucial that the aeronautical infrastructure developed to conduct SAI field research be developed on a globally cooperative and inclusive basis rather than by the military or space agencies of any single state.

\subsection{Heterogeneous preferences}

If the world were to step closer to actual SAI deployment, there is a high likelihood of heterogeneous preferences emerging among states and peoples as to the intended goals and targets of such an SAI program. A failure to converge far prior to the onset of deployment on such consensus targets could compromise the legitimacy of such a program or render deployment impossible.

In respect to temperature targets, climate preferences could diverge not merely by degree, but by sign (Lockley, 2019). In particular, Russia represents a unique challenge as a country that may be implacably opposed to re-cooling the climate (Lockley, 2019) and one with the military might to back its preference should push come to shove. While there is a general assumption that all states will prefer the pre-industrial climate (Ricke et al., 2013), the issue of heterogeneous preferences may also arise if low-latitude countries wish to overcompensate for anthropogenic warming and induce a climate cooler than the pre-industrial baseline (Heyen et al., 2015). The prospect of asking the states and peoples of the world to make selections from a climate menu may open a Pandora's Box of cacophonous heterogeneous preferences, but no SAI venture could commence before arriving at a suitable and durable consensus answer.

It is likely that focused research on global preferences and how to establish a global legitimacy process will help address the risks associated with heterogeneous preferences.

\subsection{Rash deployment in a climate emergency}

Finally, extensive pre-deployment research would equip humanity to make better subsequent decisions in the context of a perceived climate emergency. In such a situation, where intolerable damages accrue far more quickly than expected, the world may look for a panic button to push. The roughly million to one radiative forcing leverage provided by SAI (Keith, 2013) might appear to be the most salient lever at hand, and rash deployment could ensue (Horton 2019). If the cascading climate damages were sufficiently dire, a desperate plunge into a dimly lit SAI gambit might well appear to be the best among bad alternatives. The difficult scientific questions related to SAI are not how to exert a crude climate forcing, but how to do it in a fashion that maximizes benefits and minimizes harms. Should the world decide today to deprive those future climate gamblers of such knowledge, we may not stay their hands but merely blind them as they thrash forward. Comprehensive, inclusive, open, and appropriately framed research is critical to avoid misunderstandings about the readiness of the technology that might lead to rash deployment (Honegger 2020). 


\subsection{Later stage reservations}

So far, we have intentionally excluded discussion of governance risks that arise once deployment has commenced, simply because they are not temporally proximate to the decisions that researchers confront in the near term. However, to clarify that we are mindful of such risks, we will note them briefly here.

While the commercial momentum that some have hypothesized might drive SAI down a slippery slope is in fact immaterial at this early stage, if and when such a program secures sufficient funding to proceed, all the standard reservations about private greed driving public decisions apply and must be avoided. The heterogeneous preferences that were noted above will by no means abate after deployment commences and may make unitary governance of a single global program impossible, which could in turn lead either to the premature termination of the program or to a fracture into multiple, competing programs. Attribution of climate impacts to SAI forcings would prove very challenging in the event of a unitary program but would be all the more so in the context of multiple programs, rendering program optimization extremely difficult. Despite the presumed best efforts of the deployers, SAI may prove to have very unequal and potentially regionally harmful impacts, which could in turn lead either to unequal suffering, conflicts, or to the abrupt termination of such a program. Termination in the early years of a slowly ramping SAI program would be unlikely to have problematical impacts, but an abrupt termination of a substantial program would engender the dangerous warming snap-back referred to as "termination shock."

Each of these prospects presents real and substantial hazards for an SAI program and must be dealt with in turn, but all of these arise only if and after deployment has commenced, and none of them provides a justification for restricting SAI research today.

\section{Conclusions}

In this paper, we use recent literature on the deployment logistics and scale, pattern of effects, and research pathways of SAI to reinvestigate common reservations about the technology that are often put forward in a bid to restrict research in the field. We conclude that many of these reservations are no longer supported by up-to-date understandings of the field. We enumerate other research-related reservations that are material and well supported by advances in the field. In all cases, however, there is little evidence to suggest that limiting SAI research would help address these supported reservations. Instead, we argue that these supported reservations should be the focus on concerted research in the field.

Abbreviations $B E C C S$, bioenergy with carbon capture and storage; CRTs, climate response tests; $D A C C S$, direct air capture with carbon storage; $I P C C$, Intergovernmental Panel on Climate Change; $S A I$, solar aerosol injection; SCoPEx, Stratospheric Controlled Perturbation Experiment; SPICE, Stratospheric Particle Injection for Climate Engineering

Acknowledgements We thank for their helpful comments and discussion: Elizabeth Burns, David Keith, Frank Keutsch, Josh Horton, and Jesse Reynolds; Wake Smith's students Jacob Abdullah, Michael Huang, Conrad French, Isabel Gonzalez, Jonathan Li, Kobe Rizk, and Sol Thompson; and Wake Smith's son, Dillon Smith.

Code availability Not applicable 
Author contribution Wake Smith led the original study conception and design. Literature review, analysis, and interpretation were performed by Wake Smith and Claire Henly. The first draft of the manuscript was written by Wake Smith; the draft was substantially revised by Claire Henly. Both authors read and approved the final manuscript.

\section{Data availability Not applicable}

Declarations Not applicable

Conflict of interest The authors declare no competing interests.

Open Access This article is licensed under a Creative Commons Attribution 4.0 International License, which permits use, sharing, adaptation, distribution and reproduction in any medium or format, as long as you give appropriate credit to the original author(s) and the source, provide a link to the Creative Commons licence, and indicate if changes were made. The images or other third party material in this article are included in the article's Creative Commons licence, unless indicated otherwise in a credit line to the material. If material is not included in the article's Creative Commons licence and your intended use is not permitted by statutory regulation or exceeds the permitted use, you will need to obtain permission directly from the copyright holder. To view a copy of this licence, visit http://creativecommons.org/licenses/by/4.0/.

\section{References}

Ackerman F, Stanton EA (2007) The cost of climate change: what we'll pay if global warming continues unchecked. Natural Resources Defense Council, New York http://www.nrdc.org/globalwarming/cost/ cost.pdf

Arthur WB (1989) Competing technologies, increasing returns, and lock-in by historical events. The Economic Journal 99(394):116-131. https://doi.org/10.2307/2234208

Asayama S, Hulme M (2019) Engineering climate debt: temperature overshoot and peak-shaving as risky subprime mortgage lending. Climate Policy, June 14:1-10. https://doi.org/10.1080/14693062.2019. 1623165

Bellamy R, Healey P (2018) 'Slippery slope' or 'uphill struggle'? Broadening out expert scenarios of climate engineering research and development. Environ Sci Pol 83:1-10. https://doi.org/10.1016/j. envsci.2018.01.021

Bingaman DC, Rice CV, Smith W, Vogel P (2020) A stratospheric aerosol injection lofter aircraft concept: brimstone angel. AIAA Scitech 2020 Forum:22

Bodle R, Oberthür S, Donat L, Homann G, Sina S, Tedsen E (2014) Options and proposals for the international governance of geoengineering. Climate Change, Umweltbundesamt / Federal Environment Agency (Germany)

Briggs C (2013) Is geoengineering a national security risk? Geoengineering Our Climate Working Paper and Opinion Article Series

Cairns, Rose C. (2014) "Climate geoengineering: issues of path-dependence and socio-technical lock-in: climate geoengineering lock-in.” Wiley Interdisciplinary Reviews: Climate Change 5, no. 5 649-661. https://doi.org/ $10.1002 /$ wcc. 296

Callies DE (2019) The slippery slope argument against geoengineering research. Journal of Applied Philosophy 36(4):675-687. https://doi.org/10.1111/japp.12345

Chhetri N, Chong D, Conca K, Falk R, Gillespie A, Gupta A, Jinnah S, Kashwan P, Lahsen M, Light A, McKinnon C, Thiele LP, Valdivia W, Wapner P, Morrow D, Turkaly C, Nicholson S (2018) Governing solar radiation management. Washington, DC: Forum for Climate Engineering Assessment, American University. https://doi.org/10.17606/M6SM17

Crutzen PJ (2006) Albedo enhancement by stratospheric sulfur injections: a contribution to resolve a policy dilemma? Climatic Change 77(3):211-220. https://doi.org/10.1007/s10584-006-9101-y

Dai Z, Weisenstein DK, Keith DW (January 28, 2018) Tailoring meridional and seasonal radiative forcing by sulfate aerosol solar geoengineering. Geophys Res Lett 45(2):1030-1039. https://doi.org/10.1002/ 2017GL076472

Elliott, Rebecca. “Carbon capture wins fans among oil giants.” Wall Street Journal, 2020, sec. Life. https://www. wsj.com/articles/carbon-capture-is-winning-fans-among-oil-giants-11581516481 
Farrell J, McConnell K, Brulle R (March 1, 2019) Evidence-based strategies to combat scientific misinformation. Nat Clim Chang 9(3):191-195. https://doi.org/10.1038/s41558-018-0368-6

Fleming J (2010) Weather as a weapon: The troubling history of geoengineering. Slate Magazine. https://slate. com/technology/2010/09/weather-as-a-weapon-the-troubling-history-of-geoengineering.html

Floerchinger C, Dykema J, Keith D, Keutsch F (2020) A need for in situ observations to inform nearfield plume transport and aerosol dynamics as well as chemistry of alternate geoengineering materials in the stratosphere

Foust J (2019) Earth observation companies plan new satellites and seek new customers. Space News https:// spacenews.com/earth-observation-companies-plan-new-satellites-and-seek-new-customers/

Frumhoff PC, Oreskes N (2015) Fossil fuel firms are still bankrolling climate denial lobby groups. The Guardian 25

Gardiner S (2009) Is 'Arming the future' with geoengineering really the lesser evil? Some doubts about the ethics of intentionally manipulating the climate system. In: SSRN Scholarly Paper. Social Science Research Network, Rochester https://papers.ssrn.com/abstract=1357162

Hamilton C (2013a) Geoengineering: governance before research please. Our World https://ourworld.unu.edu/ en/geoengineering-governance-before-research-please

Hamilton C (2013b) Earthmasters: the dawn of the age of climate engineering. Yale University Press, New Haven

Harding A, Moreno-Cruz JB (2019) The economics of geoengineering. In: Managing Global Warming. Elsevier, pp 729-750. https://doi.org/10.1016/B978-0-12-814104-5.00025-9

Heyen D, Wiertz T, Irvine PJ (October 22, 2015) Regional disparities in SRM impacts: the challenge of diverging preferences. Clim Chang 133:557-563. https://doi.org/10.1007/s10584-015-1526-8

Holland A, Vagg X (2013) National Security Perspectives on Climate Change from Around the World. American Security Project: 10

Honegger M (2020) Chapter 3: Addressing risks and trade-offs in governance'. In: Florin M-V (Ed.) International governance issues on climate engineering. Information for policymakers; IRGC, pp 72-91. https://doi.org/10.5075/epfl-irgc-277726

Horton J (2019) Evaluating solar geoengineering deployment scenarios. In: Governance of the deployment of solar geoengineering. Harvard Project on Climate Agreements, pp 37-39

Hourdequin M (2019) Climate change, climate engineering, and the 'global poor': what does justice require? Ethics, Policy \& Environment:1-19. https://doi.org/10.1080/21550085.2018.1562525

Hubert A-M (2017) Code of conduct for responsible geoengineering research. Geoengineering Research Governance Project. http://ucalgary.ca/grgproject/

Hulme, Mike. Can science fix climate change? A case against climate engineering. New Human Frontiers Series. Cambridge: Polity Press, 2014

IPCC (2018) Summary for Policymakers. In: Global Warming of $1.5^{\circ} \mathrm{C}$. An IPCC Special Report on the impacts of global warming of $1.5^{\circ} \mathrm{C}$ above pre-industrial levels and related global greenhouse gas emission pathways, in the context of strengthening the global response to the threat of climate change, sustainable development, and efforts to eradicate poverty [Masson-Delmotte V, Zhai P, Pörtner H-O, Roberts D, Skea J, Shukla PR, Pirani A, Moufouma-Okia W, Péan C, Pidcock R, Connors S, Matthews JBR, Chen Y, Zhou X, Gomis MI, Lonnoy E, Maycock T, Tignor M, and Waterfield T (eds.)]. (in press)

Irvine P, Emanuel K, He J, Horowitz LW, Vecchi G, Keith D (2019) Halving warming with idealized solar geoengineering moderates key climate hazards. Nature Climate Change. https://doi.org/10.1038/s41558019-0398-8

Izrael YA, Zakharov VM, Petrov NN, Ryaboshapko AG, Ivanov VN, Savchenko AV, Andreev YV, Puzov YA, Danelyan BG, Kulyapin VP (May 2009) Field experiment on studying solar radiation passing through aerosol layers. Russ Meteorol Hydrol 34(5):265-273. https://doi.org/10.3103/S106837390905001X

Jamieson D (July 1996) Ethics and intentional climate change. Clim Chang 33(3):323-336

Jinnah S (2019) Building a governance foundation for solar geoengineering deployment. In: Governance of the deployment of solar geoengineering. Harvard Project on Climate Agreements, pp 37-39

Keith DW (2013) A case for climate engineering. Boston Review Books. Mass: The MIT Press, Cambridge

Keith DW, Duren R, MacMartin DG (November 17, 2014) Field experiments on solar geoengineering: report of a workshop exploring a representative research portfolio. Philos Trans R Soc A Math Phys Eng Sci 372(2031):20140175-20140175. https://doi.org/10.1098/rsta.2014.0175

Keutsch Research Group (2020) SCoPEx. Harvard University. https://projects.iq.harvard.edu/keutschgroup/ scopex

Kintisch E (2010) Hack the planet: science's best hope-or worst nightmare-for averting climate catastrophe. Wiley, Hoboken 
Lenferna A, Russotto R, Tan A, Gardiner S, Ackerman T (2017) Relevant climate response tests for stratospheric aerosol injection: a combined ethical and scientific analysis. Earth's Future. https://doi.org/10.1002/ 2016EF000504

Liebowitz S, Margolis S (1995) Path dependence, lock-in, and history. Journal of Law, Economics and Organization 11:205-226. https://doi.org/10.2139/ssrn.1706450

Lin A (2013) Does geoengineering present a moral Hazard? Ecology Law Quarterly 40(3):673-712

Lockley A (2019) Distributed governance of solar radiation management geoengineering: a possible solution to SRM's 'free-driver' problem? Frontiers of Engineering Management, October 23. https://doi.org/10.1007/ s42524-019-0055-y

MacMartin DG, Kravitz B (2019) Mission-driven research for stratospheric aerosol geoengineering. Proceedings of the National Academy of Sciences, 201811022. https://doi.org/10.1073/pnas.1811022116

Mathur V, Roy A (2019) Perspectives from India on geoengineering. Current Science 116(1):40. https://doi.org/ $10.18520 / \mathrm{cs} / \mathrm{v} 116 / \mathrm{i} 1 / 40-46$

McClellan J, Keith DW, Apt J (2012) Cost analysis of stratospheric albedo modification delivery systems. Environ Res Lett 7(3):034019

McKee M (April 13, 2017) The tobacco industry: the pioneer of fake news. Journal of Public Health Research 6(1):878-878. https://doi.org/10.4081/jphr.2017.878

McLaren DP (October 2018) Whose climate and whose ethics? Conceptions of justice in solar geoengineering modelling. Energy Res Soc Sci 44:209-221. https://doi.org/10.1016/j.erss.2018.05. 021

Morton O (2015) The planet remade: how geoengineering could change the world. Princeton University Press

Parson EA (2014) Climate engineering in global climate governance: implications for participation and linkage. Transnational Environmental Law 3(1):89-110. https://doi.org/10.1017/S2047102513000496

Philippe S (2019) Monitoring and verifying the deployment of solar geoengineering. In: Governance of the deployment of solar geoengineering. Harvard Project on Climate Agreements, pp 71-74

Pierce F (2019) Geoengineer the planet? More scientists now say it must be an option. Yale E360. https://e360. yale.edu/features/geoengineerthe-planet-more-scientists-now-say-it-must-be-an-option. Accessed 16 Jul 2020

Pierce JR, Weisenstein DK, Heckendorn P, Peter T, Keith DW (2010) Efficient formation of stratospheric aerosol for climate engineering by emission of condensable vapor from aircraft. Geophys Res Lett 37(18):L18805. https://doi.org/10.1029/2010g1043975

Preston CJ (2013) Ethics and geoengineering: reviewing the moral issues raised by solar radiation management and carbon dioxide removal. Wiley Interdisciplinary Reviews: Climate Change 4(1):23-37. https://doi.org/ 10.1002/wcc. 198

Preston CJ, Borgmann A, Buck HJ, Carr W, Clingerman F, Galarraga M, Hale B, Hourdequin M, Mercer A, Ott $\mathrm{K}$ et al (2012) Engineering the climate: the ethics of solar radiation management. Lexington Books. https:// books.google.com/books?id= 7FdtVobcAC

Rasch PJ, Tilmes S, Turco RP, Robock A, Oman L, Chen C-C, Stenchikov GL, Garcia RR (2008a) An overview of geoengineering of climate using stratospheric sulphate aerosols. Philosophical Transactions of the Royal Society A: Mathematical, Physical and Engineering Sciences 366(1882):4007-4037. https://doi.org/10. 1098/rsta.2008.0131

Rasch PJ, Crutzen PJ, Coleman DB (2008b) Exploring the geoengineering of climate using stratospheric sulfate aerosols: the role of particle size. Geophys Res Lett 35(2):L02809. https://doi.org/10.1029/ $2007 \mathrm{~g} 1032179$

Reynolds JL (2018) Governing experimental responses: negative emissions technologies and solar climate engineering. In: Jordan A, Huitema D, Van Asselt H, Forster J (eds) In Governing climate change: polycentricity in action? Cambridge University Press, Cambridge

Ricke KL, Moreno-Cruz JB, Caldeira K (2013) Strategic incentives for climate geoengineering coalitions to exclude broad participation. Environmental Research Letters 8(1):014021. https://doi.org/10.1088/17489326/8/1/014021

Roberts D (2019) Pulling CO2 out of the air and using it could be a trillion-dollar business. Vox 4 https://www. vox.com/energy-and-environment/2019/9/4/20829431/climate-change-carbon-capture-utilizationsequestration-ccu-ccs

Robock A, Bunzl M, Kravitz B, Stenchikov GL (January 29, 2010) A test for geoengineering? Science 327(5965):530-531. https://doi.org/10.1126/science.1186237

Rotman D (2013) A cheap and easy plan to stop global warming. MIT Technology Review. https://www. technologyreview.com/2013/02/08/84239/acheap-and-easy-plan-to-stop-global-warming/. Accessed 8 Jul 2020 
Scott D (2012) Insurance policy or technological fix: the ethical implications of framing solar radiation management. In: Preston CJ (ed.) Engineering the Climate: The Ethics of Solar Radiation Management. Lexington, pp 151-168

Smith W (October 2020) The cost of stratospheric aerosol injection through 2100. Environ Res Lett 15(11): 114004. https://doi.org/10.1088/1748-9326/aba7e7

Smith W, Wagner G (2018) Stratospheric aerosol injection tactics and costs in the first 15 years of deployment. Environmental Research Letters 13(12):124001. https://oi.org/10.1088/1748-9326/aae98d

Stanczyk L (2019) Some distinctions for thinking about the governance of solar geoengineering. In: Governance of the Deployment of Solar Geoengineering. Harvard Project on Climate Agreements, pp 85-87

Stilgoe J (2015) Experiment Earth: Responsible innovation in geoengineering. Routledge, Taylor \& Francis Group, New York

The Royal Society, Shepherd J (2009) Geoengineering the climate: Science, governance and uncertainty. The Royal Society, London

Victor DG (June 1, 2008) On the regulation of geoengineering. Oxf Rev Econ Policy 24(2):322-336. https://doi. org/10.1093/oxrep/grn018

Wagner G, Merk C (2019) Moral hazard and solar geoengineering. In: Governance of the deployment of solar geoengineering. Harvard Project on Climate Agreements, pp 135-139

Wagner G, Weitzman ML (2015) Climate shock: the economic consequences of a hotter planet. Popul Dev Rev 41(4):730-731. https://doi.org/10.1111/j.1728-4457.2015.00100.x

Publisher's note Springer Nature remains neutral with regard to jurisdictional claims in published maps and institutional affiliations. 